\title{
cAMP-Mediated Stabilization of Fusion Pores in Cultured Rat Pituitary Lactotrophs
}

\author{
Ana Isabel Calejo, ${ }^{1,2 \star}$ Jernej Jorgačevski, ${ }^{2,3 \star}$ Marek Kucka, ${ }^{4}$ Marko Kreft, ${ }^{2,3,5}$ Paula P. Gonçalves, ${ }^{1}$ Stanko S. Stojilkovic, \\ and Robert Zorec ${ }^{2,3}$ \\ ${ }^{1}$ The Centre for Environmental and Marine Studies, Departamento de Biologia, Universidade de Aveiro, 3810-193 Aveiro, Portugal, ${ }^{2}$ Laboratory of \\ Neuroendocrinology-Molecular Cell Physiology, Faculty of Medicine, University of Ljubljana, 1000 Ljubljana, Slovenia, ${ }^{3}$ Celica Biomedical Center, 1000 \\ Ljubljana, Slovenia, ${ }^{4}$ Section on Cellular Signaling, Developmental Neuroscience Program, National Institute of Child Health and Human Development, \\ National Institutes of Health, Bethesda, Maryland 20892-4510, and 5Department of Biology, Biotechnical Faculty, University of Ljubljana, Ljubljana, 1000, \\ Ljubljana, Slovenia
}

Regulated exocytosis mediates the release of hormones and transmitters. The last step of this process is represented by the merger between the vesicle and the plasma membranes, and the formation of a fusion pore. Once formed, the initially stable and narrow fusion pore may reversibly widen (transient exocytosis) or fully open (full-fusion exocytosis). Exocytosis is typically triggered by an elevation in cytosolic calcium activity. However, other second messengers, such as cAMP, have been reported to modulate secretion. The way in which cAMP influences the transitions between different fusion pore states remains unclear. Here, hormone release studies show that prolactin release from isolated rat lactotrophs stimulated by forskolin, an activator of adenylyl cyclases, and by membrane-permeable cAMP analog (dbcAMP), exhibit a biphasic concentration dependency. Although at lower concentrations (2-10 $\mu \mathrm{m}$ forskolin and 2.5-5 mM $\mathrm{dbcAMP})$ these agents stimulate prolactin release, an inhibition is measured at higher concentrations $(50 \mu \mathrm{m}$ forskolin and $10-15 \mathrm{~mm}$ dbcAMP). By using high-resolution capacitance $\left(C_{m}\right)$ measurements, we recorded discrete increases in $C_{m}$, which represent elementary exocytic events. An elevation of cAMP leaves the frequency of full-fusion events unchanged while increasing the frequency of transient events. These exhibited a wider fusion pore as measured by increased fusion pore conductance and a prolonged fusion pore dwell time. The probability of observing rhythmic reopening of transient fusion pores was elevated by dbcAMP. In conclusion, cAMP-mediated stabilization of wide fusion pores prevents vesicles from proceeding to the full-fusion stage of exocytosis, which hinders vesicle content discharge at high cAMP concentrations.

\section{Introduction}

Regulated exocytosis mediates the release of hormones and transmitters stored in vesicles (Jahn et al., 2003). This process ends with the merger of the vesicle membrane and the plasma membrane, leading to the formation of a stable and narrow fusion pore, through which secretions exit the cell (Spruce et al., 1990; Lollike et al., 1995; Vardjan et al., 2007). An increase in cytosolic calcium concentration $\left(\left[\mathrm{Ca}^{2+}\right]_{\mathrm{i}}\right)$ leads to the fusion pore diameter increase, which eventually either fully opens (full-fusion exocytosis) or reversibly closes (transient exocytosis) (Vardjan et al.,

Received Nov. 19, 2012; revised March 11, 2013; accepted April 1, 2013.

Author contributions: A.I.C., J.J., S.S.S., and R.Z. designed research; A.I.C., J.J., and M. Kucka performed research; M. Kreft contributed unpublished reagents/analytic tools; A.I.C. and M. Kucka analyzed data; A.I.C., J.J., M. Kucka, P.P.G., S.S.S., and R.Z. wrote the paper.

This work was supported by the Ministry of Higher Education, Sciences, and Technology of the Republic of Slovenia (P3 310; J3 3654; J3 4051; J3 4146), the Portuguese Foundation of Science and Technology of the Portuguese Ministry of Sciences, Technology, and High Education (Bilateral Agreement between Portugal and Slovenia; Project 441.00 SLOVENIA, SFRH/BD/41217/2007 to A.I.C.), and the National Institute of Child Health and Human Development Intramural.

The authors declare no competing financial interests.

${ }^{*}$ A.I.C. and J.J. contributed equally to this work.

Correspondence should be addressed to Dr. Robert Zorec, University of Ljubljana, Faculty of Medicine, Institute of Pathophysiology, LN-MCP, Zaloška 4, 1000 Ljubljana, Slovenia. E-mail: robert.zorec@mf.uni-lj.si.

DOI:10.1523/JNEUROSCI.5351-12.2013

Copyright $\odot 2013$ the authors $\quad 0270-6474 / 13 / 338068-11 \$ 15.00 / 0$
2007; Jorgačevski et al., 2008). Fluctuations between fusion pore states with different diameters have been reported, lasting from milliseconds to minutes before full-fusion (Fernandez et al., 1984; Vardjan et al., 2007; Jorgačevski et al., 2010). These fluctuations can exhibit remarkable rhythmicity (Henkel et al., 2000; Stenovec et al., 2004; Vardjan et al., 2007), but their nature remains elusive.

Changes in $\left[\mathrm{Ca}^{2+}\right]_{\mathrm{i}}$ are likely to play a role in regulating the transitions between stages of exocytosis (Alés et al., 1999; Jorgačevski et al., 2008). Additionally, elevations in cAMP affect exocytosis (Renström et al., 1997; Sikdar et al., 1998; Cochilla et al., 2000; Kostic et al., 2002; Sedej et al., 2005; Gonzalez-Iglesias et al., 2006), but it is less clear exactly which exocytic stages are modulated by cAMP. In lactotrophs, cAMP facilitates hormone release via several mechanisms (Gonzalez-Iglesias et al., 2006, 2008; Stojilkovic et al., 2010), also by affecting the exocytic machinery (Sikdar et al., 1990). Interestingly, cAMP may shift fullfusion to transient exocytosis, as shown in insulin-secreting cells (Hanna et al., 2009). In contrast, in melanotrophs, cAMP mediates preferential fusion of larger vesicles without increasing the frequency of events (Sikdar et al., 1998).

To investigate the nature of the transitions between stages vesicles undergo in regulated exocytosis, we studied peptidergic vesicles of rat pituitary lactotrophs, cells in which unitary exo- 
cytic events can be studied (Stenovec et al., 2004; Jorgačevski et al., 2008). We first asked how elevations in intracellular cAMP affect hormone release from the population of lactotrophs. The results revealed a biphasic effect of cAMP. At relatively low cAMP elevations, prolactin (PRL) release was augmented, whereas a decreased release in PRL was recorded at higher cAMP levels. Next, the cell-attached patch-clamp was used to monitor discrete changes in membrane capacitance $\left(\mathrm{C}_{\mathrm{m}}\right)$, which represent unitary exocytic events (Neher and Marty, 1982) and permit measurements of fusion pore conductance $\left(G_{p}\right)$ and fusion pore dwell time (Lollike and Lindau, 1999; Jorgačevski et al., 2008, 2011). Elevations in cAMP increased the frequency of transient, but not full-fusion, events. Transient fusion pore openings exhibited increased $G_{p}$ and prolonged fusion pore dwell time. Moreover, cAMP increased the probability of rhythmic reopenings of transient fusion pores. Although cAMP increased the frequency of unitary exocytic events, cAMP-mediated stabilization of widely open transient fusion pores may hinder the discharge of vesicle contents.

\section{Materials and Methods}

Cell cultures. Lactotrophs were isolated from adult male Wistar rats as described previously (Ben-Tabou et al., 1994). Briefly, cells were plated on glass coverslips coated with poly-L-lysine and maintained in the feeding medium (high-glucose DMEM supplemented with 10\% newborn calf serum $1.5 \mu \mathrm{M}$ BSA and $2 \mathrm{~mm}$ L-glutamine) in an atmosphere of humidified air $(95 \%)$ and $\mathrm{CO}_{2}(5 \%)$ at $37^{\circ} \mathrm{C}$. The feeding medium was replaced every other day. The animals were killed in accordance with the International Guiding Principles for Biomedical Research Involving Animals developed by the Council for International Organizations of Medical Sciences, the Directive on Conditions for Issue of License for Animal Experiments for Scientific Research Purposes (Official Gazette of the Republic of Slovenia 40/85 and 22/87), and the National Institute of Child Health and Human Development Animal Care and Use Committee. The procedures using animals were approved by the Veterinary Administration of the Republic of Slovenia (approval no. 3440-29/ 2006). Experiments were performed at room temperature 1-4 d after the isolation.

$P R L$ release and cAMP measurements. $P R L$ and cAMP release was monitored using cell column perfusion experiments. Briefly, $1.2 \times 10^{7}$ cells were incubated with preswollen cytodex-1 beads in $60 \mathrm{~mm}$ Petri dishes for $18 \mathrm{~h}$. The beads were then transferred to $0.5 \mathrm{ml}$ chambers and perifused with Hanks' M199 containing 25 mM HEPES, 0.1\% BSA, and penicillin $(100 \mathrm{U} / \mathrm{ml}) /$ streptomycin $(100 \mu \mathrm{g} / \mathrm{ml})$ for $2.5 \mathrm{~h}$ at a flow rate of 0.8 $\mathrm{ml} / \mathrm{min}$ and at $37^{\circ} \mathrm{C}$ to establish stable basal secretion. Fractions were collected at $1 \mathrm{~min}$ intervals and later assayed for PRL and cAMP contents using radioimmunoassay. The primary antibody and standard for PRL assay were purchased from the National Pituitary Agency and Dr. A.F. Parlow (Harbor-UCLA Medical Center, Torrance, California). cAMP was determined using specific antiserum provided by Albert Baukal (National Institute of Child Health and Human Development, Bethesda, Maryland). ${ }^{125}$ I-PRL and ${ }^{125}$ I-cAMP were purchased from PerkinElmer Life Sciences.

Electrophysiology. Glass pipettes were fire-polished and heavily coated with Sylgard (Midland). The resistance of pipettes was 3-6 M $\Omega$. Cellattached capacitance measurements were performed with a dual-phase lock-in patch-clamp amplifier (SWAM IIC; Celica) as described previously (Vardjan et al., 2007, Jorgačevski et al., 2010). A sine wave voltage $(1591 \mathrm{~Hz}, 111 \mathrm{mV}$ r.m.s.) was applied to the pipette while holding the pipette potential at $0 \mathrm{mV}$. The phase of the dual-phase lock-in amplifier was adjusted and checked at regular intervals as described previously (Vardjan et al., 2007; Jorgačevski et al., 2010). We performed capacitance measurements under nonstimulated conditions and after stimulation with different cAMP-increasing agents: $1 \mathrm{mM}$ IBMX (3-isobutyl-1methylxanthine, a phosphodiesterase inhibitor to increase cytosolic cAMP concentration), $10 \mathrm{~mm}$ dbcAMP $\left(\mathrm{N}^{6}, 2^{\prime}\right.$-O-dibutyryl adenosine$3^{\prime}, 5^{\prime}$-cyclic monophosphate, a membrane-permeable cAMP analog), and $1 \mu \mathrm{M}$ forskolin. dbcAMP and IBMX were added as a bolus of the stock solutions, which were prepared in extracellular solution. Stimulation with forskolin was performed by a 30 min preincubation of cells with forskolin.

Data analysis. Electrophysiological recordings were analyzed in the custom-made software (CellAn) written for MATLAB (MathWorks). For transient fusion events, vesicle capacitance $\left(\mathrm{C}_{\mathrm{v}}\right)$ and $\mathrm{G}_{\mathrm{p}}$ were calculated from the imaginary $(\mathrm{Im})$ and the real (Re) part of the admittance signals, as reported previously (Lollike and Lindau, 1999): $C_{v}=\left[\left(\operatorname{Re}^{2}+\right.\right.$ $\left.\left.\mathrm{Im}^{2}\right) / \mathrm{Im}\right] / \omega$, where $\omega$ is the angular frequency $(\omega=2 \mathrm{if}, \mathrm{f}$ is the sine-wave frequency, $1591 \mathrm{~Hz})$, and $\mathrm{G}_{\mathrm{p}}=\left(\mathrm{Re}^{2}+\mathrm{Im}^{2}\right) / \mathrm{Re}$. Fusion-pore radius was estimated by using the equation $\mathrm{G}_{\mathrm{p}}=\left(\pi r^{2}\right) /(\rho \lambda)$, where $\mathrm{r}$ denotes fusion pore radius, $\rho$ the estimated resistivity of the saline $(100 \Omega \mathrm{cm})$, and $\lambda$ the length of a gap junction channel (15 nm; Spruce et al., 1990). Vesicle diameter was calculated by using specific membrane capacitance $\left(\mathrm{c}_{\mathrm{m}}\right)$ of $8 \mathrm{fF} / \mu \mathrm{m}^{-2}$.

A burst was considered to consist of no less than five transient events, with no more than $5 \mathrm{~s}$ between the ensuing events. Transient events in a burst were considered periodic when times between the ensuing events were normally distributed (Shapiro-Wilk normality test) and the coefficient of variation of the Gaussian curve fitted to the data was $<0.2$.

All statistics were performed with Sigma Plot (Systat Software). Results are presented as mean \pm SEM. Statistical significance was evaluated by using Student's $t$ test for normally and Mann-Whitney for non-normally distributed data: $p<0.05\left(^{*}\right)$ and $p<0.01\left(^{* *}\right)$.

Solutions. The extracellular solution consisted of $10 \mathrm{~mm}$ HEPES/ $\mathrm{NaOH}$, pH 7.4, $10 \mathrm{~mm}$ D-glucose, $130 \mathrm{~mm} \mathrm{NaCl}, 8 \mathrm{~mm} \mathrm{CaCl}_{2}, 1 \mathrm{~mm}$ $\mathrm{MgCl}_{2}$, and $5 \mathrm{~mm} \mathrm{KCl}$. Unless stated otherwise, all chemicals of highest purity available were purchased from Sigma-Aldrich.

\section{Results}

\section{The effect of cAMP-increasing agents on cAMP and PRL release in pituitary cells}

cAMP is a secondary messenger capable of enhancing hormone release by promoting $\mathrm{Ca}^{2+}$ influx into cells or by directly modulating specific steps in the secretory pathway (for review, see Seino and Shibasaki, 2005). Previously, we have confirmed a linear relationship between intracellular and extracellular cyclic nucleotide concentrations in lactotrophs treated with cAMPincreasing agents (Gonzalez-Iglesias et al., 2006). Forskolin, an adenylyl cyclase activator, dose-dependently (added to the culture medium at 2, 10, and $50 \mu \mathrm{M}$; see Fig. $1 a$ ) increased the concentration of released cAMP in cultured cells, as reported previously (Gonzalez-Iglesias et al., 2006). To determine whether forskolin also affects the release of hormones from lactotrophs, we measured PRL release from perfused pituitary lactotrophs when forskolin was applied for a period of $40 \mathrm{~min}$ (Fig. 1b). At lower concentrations of forskolin $(2$ and $10 \mu \mathrm{M})$, PRL release was enhanced immediately after the addition of forskolin and reached a steady-state that was 1.6-fold higher than in controls. However, at a higher concentration of forskolin $(50 \mu \mathrm{M})$, PRL release increased only after a delay of $30 \mathrm{~min}$ (Fig. 1b). Because different concentrations of forskolin had different effects on PRL release from lactotrophs, we wanted to determine whether this effect was specific for forskolin. Next, we used dbcAMP, a membranepermeable cAMP analog. In Figure $1 c$, the results show that dbcAMP increased PRL release by 1.5 -fold at 2.5 and $5 \mathrm{~mm}$. However, the addition of $10 \mathrm{~mm}$ dbcAMP decreased the rate of PRL release, which reached levels lower than those recorded in controls. At $15 \mathrm{~mm}$ dbcAMP, the rate of PRL release continued to decrease but reverted to partial recovery upon rinsing dbcAMP from the bath.

These results indicate that cAMP potentiates PRL release at relatively low concentrations, whereas at higher cAMP concentrations it inhibits PRL release. Therefore, our next goal was to 

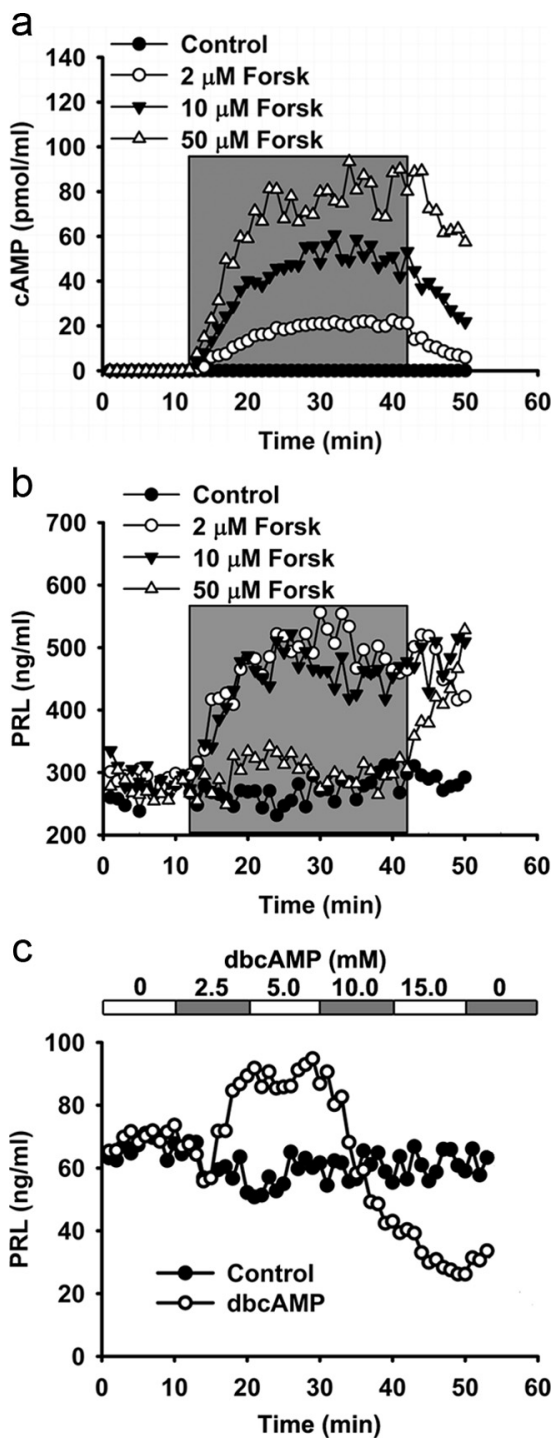

Figure 1. Elevation in CAMP cytosolic concentration increases PRL release from perfused pituitary lactotrophs. Cultured pituitary lactotrophs were perfused with extracellular solutions containing different concentrations of forskolin (Forsk), an adenyl cyclase activator, and dbcAMP. Samples were collected every minute and analyzed for either CAMP or PRL. $\boldsymbol{a}$, Dosedependent effect of forskolin on CAMP release in perfused lactotrophs. Gray represents the period of forskolin application. $\boldsymbol{b}$, Dose-dependent effect of forskolin on PRL release from perfused lactotrophs. Gray represents the period of forskolin application. $c$, The effect of different concentrations of dbcAMP on the PRL release from perfused lactotrophs. The top $x$-axis represents the concentrations of applied dbcAMP. Shown are representative experiments from four independent experiments.

study how cAMP-increasing agents affect the exocytic machinery directly. To this end, we recorded unitary exocytic events by the high-resolution membrane capacitance technique (Neher and Marty, 1982; Zorec et al., 1991).

cAMP increases the frequency of transient exocytic events Although single-fusion events can be studied in single cells (Kreft and Zorec, 1997; Vardjan et al., 2007; Jorgačevski et al., 2008), few studies address the question of how cAMP modulates unitary exocytotic events (Sikdar et al., 1998; Hanna et al., 2009). Here, we studied the effects of cAMP on the occurrence and on the properties of the unitary exocytic events of PRL-containing vesicles. We used the cell-attached patch-clamp technique to monitor $\mathrm{C}_{\mathrm{m}}$, a parameter linearly related to the plasma membrane surface area in control conditions (extracellular solution) and in the presence of different cAMP-increasing agents. To elevate cAMP levels, we applied IBMX, a nonspecific phosphodiesterase inhibitor $(1 \mathrm{mM})$, and forskolin $(1 \mu \mathrm{M})$, in two separate sets of experiments, both of which have been shown to increase cAMP and PRL release from lactotrophs (Fig. 1b) (Gonzalez-Iglesias et al., 2006). We performed an additional set of experiments where we applied $10 \mathrm{~mm}$ dbcAMP, which inhibits PRL release (Fig. 1c).

The recordings were made from 50 membrane patches, each on a different cell, with a total recording time of $13.9 \mathrm{~h}(3.2 \mathrm{~h}$ at control conditions and $10.7 \mathrm{~h}$ at stimulated conditions) and at an average time of $1000 \mathrm{~s}$ per recording. We observed the presence of discrete irreversible upward and downward steps in $\mathrm{C}_{\mathrm{m}}$, likely indicating full-fusion exocytosis and endocytosis, respectively (Heuser and Reese, 1973; Neher and Marty, 1982) (Fig. 2a). We also recorded reversible steps in $\mathrm{C}_{\mathrm{m}}$ that likely represent transient exocytosis (Alvarez de Toledo et al., 1993; Fesce et al., 1994; Jorgačevski et al., 2008) (Fig. 2b). Transient exocytic events, observed in the imaginary part of the admittance trace (Im), often exhibited a crosstalk, observed on the real part of the admittance trace $(\mathrm{Re})$, indicating the presence of a narrow fusion pore (Lollike and Lindau, 1999) (Fig. 2b). For these events, we calculated the vesicle capacitance $\left(\mathrm{C}_{\mathrm{v}}\right)$ and fusion pore conductance $\left(G_{p}\right)$, as described in Materials and Methods (Fig. 2c) (Lollike and Lindau, 1999). The average $C_{v}$ amplitude of exocytic events recorded in control and in stimulated conditions was $0.88 \pm 0.03 \mathrm{fF}$ (range, $0.2-4 \mathrm{fF}$ ). By assuming specific membrane capacitance of $8 \mathrm{fF} / \mu \mathrm{m}^{-2}$ and spherical geometry of vesicles, the amplitude corresponds to vesicle diameter of $176 \pm 10 \mathrm{~nm}$, which is in agreement with previously published results on PRL-containing vesicles (Smets et al., 1987; Angleson et al., 1999; Vardjan et al., 2007, Jorgačevski et al., 2008, 2011).

The occurrence of irreversible upward events did not significantly change after the addition of any of the cAMP-increasing agents (Fig. $2 d$, black bars; Table 1). However, both IBMX and forskolin applications increased the occurrence of transient exocytic events twofold: from $0.06 \pm 0.01 \mathrm{~s}$ to $0.11 \pm 0.01 \mathrm{~s}(p<$ $0.01)$ and to $0.11 \pm 0.02 \mathrm{~s}(p<0.05)$, respectively (Fig. $2 d$, open bars). The stimulation with dbcAMP elicited an even greater increase in the frequency of transient exocytic events, to $0.18 \pm$ $0.02 \mathrm{~s}$ (Fig. $2 d$, open bars $p<0.01$ ). Observed changes were not an artifact of the vehicle (20 mM DMSO) because control experiments where we added the vehicle without cAMP increasing agents did not affect the frequency of transient exocytic events (data not shown).

The inverse linear relation between the occurrences of reversible (transient) versus irreversible (full-fusion) exocytic events indicates that CAMP stimulation augments the former while inhibiting the latter events (Fig. 2e), which is consistent with the view that cAMP upregulates the transient mode of exocytosis (Hanna et al., 2009). We also observed that the nature of appearance of transient exocytic events was different after stimulation. Before the stimulation, transient exocytic events usually occurred as independent events, whereas after the addition of dbcAMP, they often appeared in bursts (Fig. $2 f$ ).

Figure $3 a$ shows the $C_{v}$ amplitude distribution of transient exocytic events recorded in a representative patch of membrane. There is unchanged $\mathrm{C}_{\mathrm{v}}$ amplitude before and after dbcAMP application (Gaussian mean $1.09 \pm 0.05 \mathrm{fF} ; n=11$ and $1.08 \pm 0.01$ fF; $n=64$ ), indicating that dbcAMP stimulation modulated the properties of a preexisting fusion pore. To determine whether transient events in $\mathrm{C}_{\mathrm{m}}$ represent the repetitive fusion pore opening of a single vesicle, we compared the $\mathrm{C}_{\mathrm{v}}$ amplitudes of upward 
a

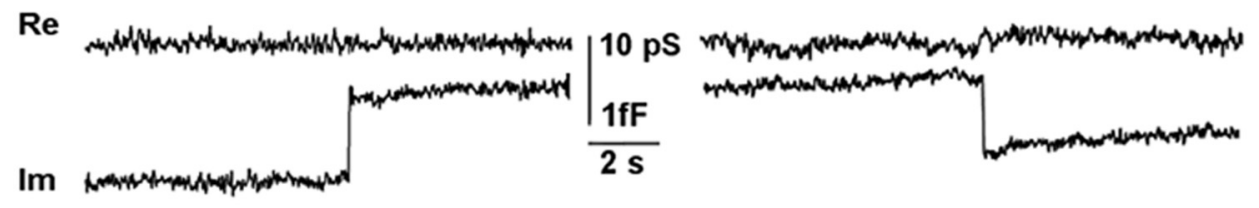

b Control

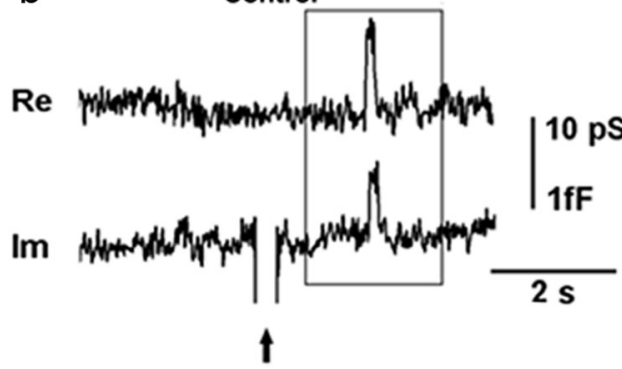

+ dbcAMP

C

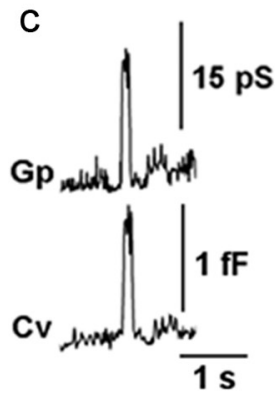

d

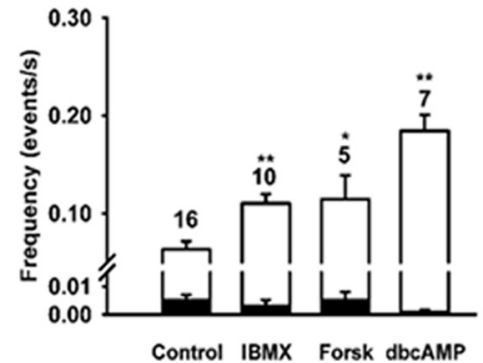

e

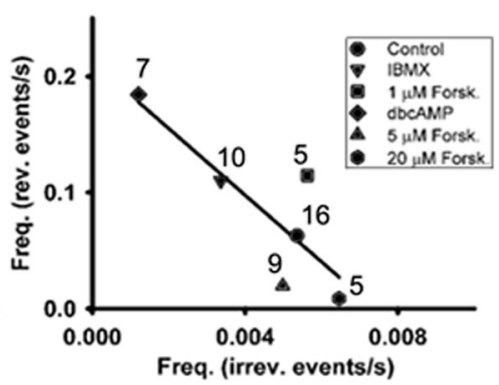

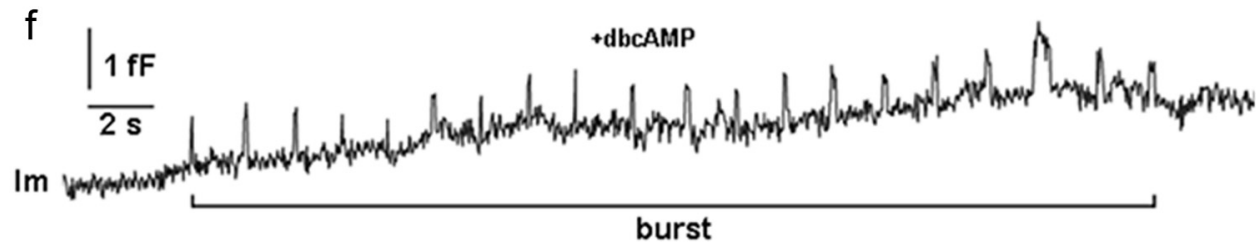

Figure 2. cAMP-increasing agents augment the frequency of reversible, but not the irreversible, discrete capacitance steps. The irreversible events are represented by discrete upward or downward step in the imaginary admittance trace $(\mathrm{Im})$, which is proportional to the membrane capacitance. Reversible events consist of an upward and a subsequent downward discrete step in Im, which follows within 5 s. $\boldsymbol{a}$, A representative example of irreversible upward (left) and downward steps (right) in Im trace and the corresponding real part of the admittance trace (Re, top). $\boldsymbol{b}$, Reversible events in Im before (Control, left) and after the stimulation by dbcAMP (10 mm, +dbcAMP, right). Some of the reversible events in Im trace exhibit projections to the Re trace. ${ }^{*}$ Others were devoid of projections. Arrows indicate calibration pulses in Im, used to adjust the phase of the lock-in amplifier. $c$, Projected reversible events were used to calculate $G_{p}$ and $C_{v}$, as described in Materials and Methods. Shown is a representative example framed in $\boldsymbol{b}$. $\boldsymbol{d}$, The average frequency of irreversible upward events (filled bars) in controls was $0.005 \pm 0.002 \mathrm{~s}(n=16)$. The addition of phosphodiesterase inhibitor (IBMX, $1 \mathrm{mM}$ ), an agent to activate adenylyl cyclase (forskolin $1 \mu \mathrm{M}$, Forsk), and a membrane-permeable cAMP analog (dbcAMP, $10 \mathrm{~mm})$ did not affect $(p>0.05)$ the frequency of irreversible upward events $(0.003 \pm 0.002,0.006 \pm 0.002$, and $0.001 \pm 0.001 \mathrm{~s})$, respectively. The average frequency of reversible events (open bars) increased from $0.06 \pm 0.01 \mathrm{sin}$ controls to $0.11 \pm 0.01 \mathrm{~s}\left({ }^{* *} p<0.01 ; \mathrm{IBMX}\right), 0.11 \pm 0.02 \mathrm{~s}\left({ }^{*} p<0.05\right.$; forskolin), and $0.18 \pm 0.02 \mathrm{~s}\left({ }^{* *} p<0.01 ; \mathrm{dbCAMP}\right)$. Values are mean \pm SEM. Numbers above error bars indicate the number of patches. $\boldsymbol{e}$, We observed negative relationships between the average frequency of irreversible upward events and the average frequency of reversible events for each condition, which was best fitted with the linear regression: $y$ (the average frequency of reversible events) $=(-21 \pm 9) \times x$ (the average frequency of irreversible upward events) $+(0.20 \pm 0.04)$ with the correlation coefficient, $r=0.85 . f$, Representative Im trace, showing a burst of reversible events. We defined a burst as a minimum of five reversible events with $<5 \mathrm{~s}$ between ensuing reversible events.

Table 1. Types of unitary exocytic events in controls and in the presence of dbcAMP

\begin{tabular}{|c|c|c|c|}
\hline \multirow[b]{2}{*}{$\begin{array}{l}\text { Type of exocytic } \\
\text { events }\end{array}$} & \multicolumn{3}{|c|}{ Percentage of different exocytic events } \\
\hline & $\begin{array}{l}\text { Full-fusion events (no. of } \\
\text { events/all events) }\end{array}$ & $\begin{array}{l}\text { Transient events with } \\
\text { wide fusion pores } \\
\text { (no. of events/all } \\
\text { events) }\end{array}$ & $\begin{array}{l}\text { Transient events with } \\
\text { narrow fusion pores } \\
\text { (no. of events/all } \\
\text { events) }\end{array}$ \\
\hline Control & $\begin{array}{l}8.3 \% \\
(n=25 / 300)\end{array}$ & $\begin{array}{l}66.6 \% \\
(n=200 / 300)\end{array}$ & $\begin{array}{l}25.0 \% \\
(n=75 / 300)\end{array}$ \\
\hline$+\mathrm{dbcAMP}$ & $\begin{array}{l}0.6 \% \\
(n=7 / 1152)\end{array}$ & $\begin{array}{l}98.5 \% \\
(n=1136 / 1152)\end{array}$ & $\begin{array}{l}0.9 \% \\
(n=9 / 1152)\end{array}$ \\
\hline
\end{tabular}

and downward steps in this recording. Regression lines for control ( $n=11$ events, filled circles) and dbcAMP-stimulated conditions ( $n=64$ events, open circles) had slopes close to 1 $(1.0 \pm 0.1$ and $0.8 \pm 0.1$, respectively; Fig. 3aii) and high correlation coefficients ( $r=0.95$ and $r=0.78$, respectively; Fig. 3aii). These results are consistent with the view that transient exocytic events represent a single vesicle interacting with the plasma membrane. To further test whether this is valid for all patches, we compared the average upward and downward amplitudes in $\mathrm{C}_{\mathrm{v}}$ in controls $(n=16$ cells) and after cAMP stimulation $(n=21$ cells). Similarly as for the single patch, the results were best fitted 

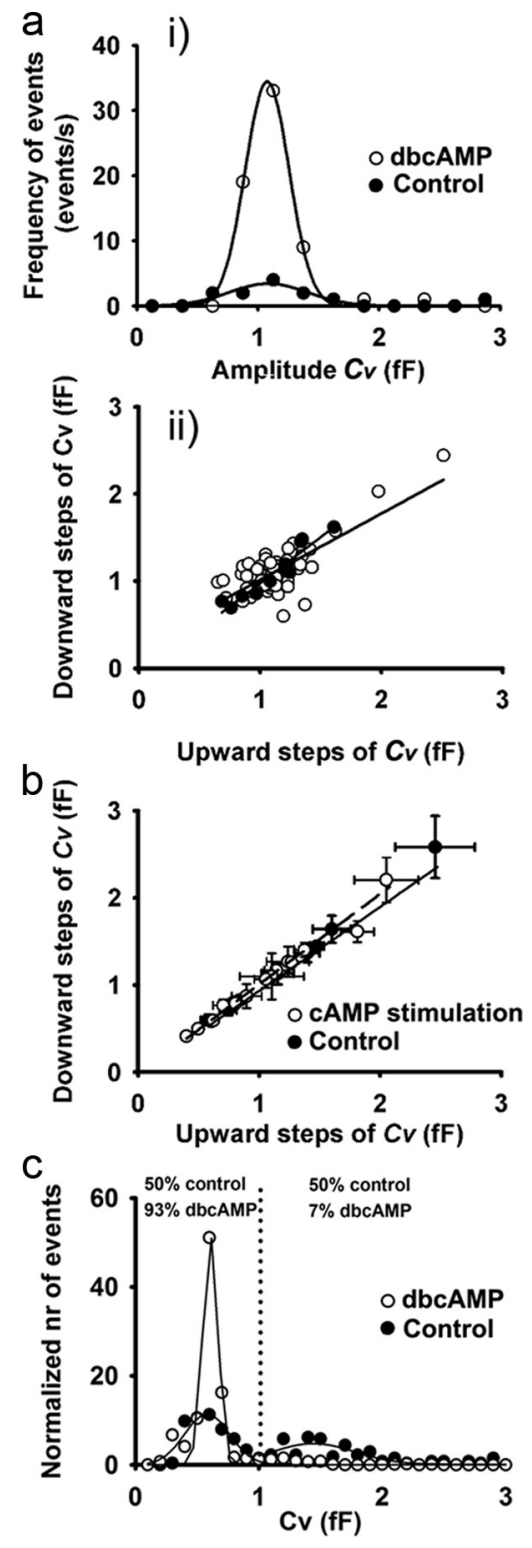

Figure 3. Reversible events mirror repetitive fusion of single vesicle. $a$ i, The distributions of vesicle membrane capacitance $\left(C_{\mathrm{V}}\right)$ amplitudes of reversible events from a representative patch, before and after the stimulation with dbcAMP, were similar. Lines show fitted Gaussian curves with means of $1.09 \pm 0.05 \mathrm{fF}$ (control, correlation coefficient $r=0.92 ; n=11$ events) and $1.08 \pm 0.01 \mathrm{fF}$ (dbcAMP, $r=0.99 ; n=64$ events), respectively. aii, The relationship between amplitudes of the downward and the preceding upward $C_{V}$ steps of reversible events: the regression line represents the best fit with parameters: $y\left(C_{v}\right.$ amplitude of the downward step $)=(1.0 \pm 0.1) \times x\left(C_{v}\right.$ amplitude of the upward step $)+(-0.1 \pm 0.1)\left(r=0.95, n=11\right.$ events) before stimulation and the regression line $y\left(C_{v}\right.$ amplitude of the downward step $)=(0.8 \pm 0.1) \times x\left(C_{v}\right.$ amplitude of the upward step $)+(0.26 \pm$ $0.10)(r=0.76, n=64$ events) after the stimulation (open circles). The slopes of both regression lines were similar $(p=0.2) \cdot \boldsymbol{b}$, The relationship between the average $C_{v}$ amplitudes of downward versus upward discrete steps of reversible events in distinct membrane patches before and after the addition of cAMP-increasing agents. The solid line represents linear fit of the controls: $y$ (the average $C_{v}$ amplitudes of downward steps $)=(0.97 \pm 0.04) \times x$ (the average $C_{v}$ amplitudes of upward steps $)+$ $(-0.03 \pm 0.15)(r=0.99, n=9$ cells $)$, and the hyphenated line represents linear fit to the data obtained after the addition of CAMP-increasing agents: $y$ (the average $C_{v}$ amplitudes of upward steps $)=(1.04 \pm 0.02) \times x$ (the average $C_{v}$ amplitudes of downward steps $)+(-0.03 \pm 0.05)$ $(r=0.99, n=16$ cells). The slopes of both regression lines were similar $(p=0.3)$. Values are

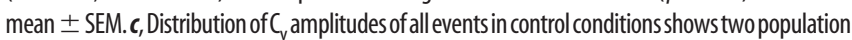
best fitted with Gaussian curves with means: $0.58 \pm 0.01 \mathrm{fF}(r=0.82)$ and $1.44 \pm 0.02 \mathrm{fF}(r=0.80)$, each corresponding to $50 \%$ of all events in control conditions. After dbcAMP, we only observed one population best fitted with Gaussian curve with mean $0.61 \pm 0.01 \mathrm{fF}(r=0.99)$ that represents $93 \%$ of all events after dbcAMP. with the regression line with the slope near $1(0.97 \pm 0.04$ for control and $1.04 \pm 0.02$ after stimulation) and with even higher correlation coefficients ( $r=0.99$ and 0.99 , respectively; Fig. $3 b$ ). We also investigated whether the stimulation by cAMP affects the distribution of $\mathrm{C}_{\mathrm{v}}$ amplitudes of transient exocytic events. Figure $3 c$ shows that, in controls, the distribution of $\mathrm{C}_{\mathrm{v}}$ amplitudes consisted of two peaks (with mean amplitudes of $0.58 \pm 0.01 \mathrm{fF}$ and $1.44 \pm 0.02 \mathrm{fF}$ ), indicating two populations of vesicles interacting with the plasma membrane. However, after stimulation by cAMP, the predominant vesicle population that interacted with the plasma membrane exhibited a lower $\mathrm{C}_{\mathrm{v}}$ amplitude of $0.61 \pm$ $0.01 \mathrm{fF}$. This population of vesicles represented $50 \%$ of all vesicles interacting with the plasma membrane in controls, whereas it increased to $93 \%$ after cAMP stimulation.

These results indicate that stimulation by cAMP primarily affects smaller peptidergic vesicles, which are engaged in transient mode of exocytosis.

\section{cAMP affects the fusion pore diameter and dwell time}

In the transient mode of exocytosis, vesicle cargo discharge can be constrained by a narrow fusion pore and by the relatively short effective fusion pore dwell time (Barg et al., 2002; Tsuboi and Rutter, 2003; Stenovec et al., 2004; Obermüller et al., 2005). Therefore, our next aim was to determine whether cAMPincreasing agents alter the fusion pore geometry. Thus, we calculated fusion pore conductance $\left(G_{p}\right.$; Fig. $2 c$, see Materials and Methods) (Lollike and Lindau, 1999), a parameter related to the fusion pore diameter (Breckenridge and Almers, 1987). However, $G_{p}$ can only be calculated for transient fusion events exhibiting a significant crosstalk between the Im (proportional to the vesicle capacitance $\mathrm{C}_{\mathrm{v}}$ ) and the Re traces. In this case, a relatively narrow fusion pore acts as a resistor, which produces a measurable projection to the Re part of the admittance signal (reflecting the conductance of the fusion pore) (Lollike and Lindau, 1999).

The majority of transient fusion events, observed in controls and in dbcAMP-stimulated conditions, exhibited wide fusion pores. Stimulation with dbcAMP increased the percentage of transient exocytic events with wide fusion pores from $67 \%$ to 99\% (Table 1). Transient exocytic events with narrow fusion pores decreased from $25 \%$ in controls to $\sim 1 \%$ after treatment with dbcAMP (Table 1). In addition, the percentage of full-fusion events decreased after stimulation with dbcAMP from $8 \%$ (control) to $<1 \%$ (Table 1$)$.

To learn about the influence of each of the cAMP-enhancing agents on $G_{p}$ in detail, we analyzed the average $G_{p}$ in each set of experiments, respectively (Fig. $4 a$ ). After the treatment with IBMX, the average $G_{p}$ was $21 \pm 1 \mathrm{pS}$ ( $n=139$ events), similar to the average $\mathrm{G}_{\mathrm{p}}$ in controls ( $23 \pm 2 \mathrm{pS} ; n=75$ events; Fig. $4 a$ ). However, a significant increase in the average $G_{p}$ was observed after the treatment by forskolin and dbcAMP: $30 \pm 1 \mathrm{pS}(n=141$; $p<0.01)$ and $32 \pm 6 \mathrm{pS}(n=9 ; p<0.05$; Fig. $4 a)$, respectively. Interestingly, if we analyzed the cAMP-mediated change in fusion pore conductance as a function of $\mathrm{C}_{\mathrm{v}}$, the results revealed that larger vesicles with $C_{v}>1 \mathrm{fF}$ exhibited larger $G_{p}$ than events with $\mathrm{C}_{\mathrm{v}}<1 \mathrm{fF}$ (Fig. $4 b$ ).

The dwell time of transient fusion pore openings was measured as the time between the upward and the ensuing downward step in $\mathrm{C}_{\mathrm{m}}$, as reported (Vardjan et al., 2007; Jorgačevski et al., 2008). Stimulation with IBMX or forskolin did not affect the average fusion pore dwell time $(0.19 \pm 0.02 \mathrm{~s}$ in control vs $0.19 \pm$ $0.02 \mathrm{~s}$ with IBMX and $0.21 \pm 0.02 \mathrm{~s}$ with forskolin). However, stimulation with dbcAMP doubled the average fusion pore dwell time to $0.40 \pm 0.02 \mathrm{~s}(p<0.01$; Fig. $4 c)$. The probability of the 

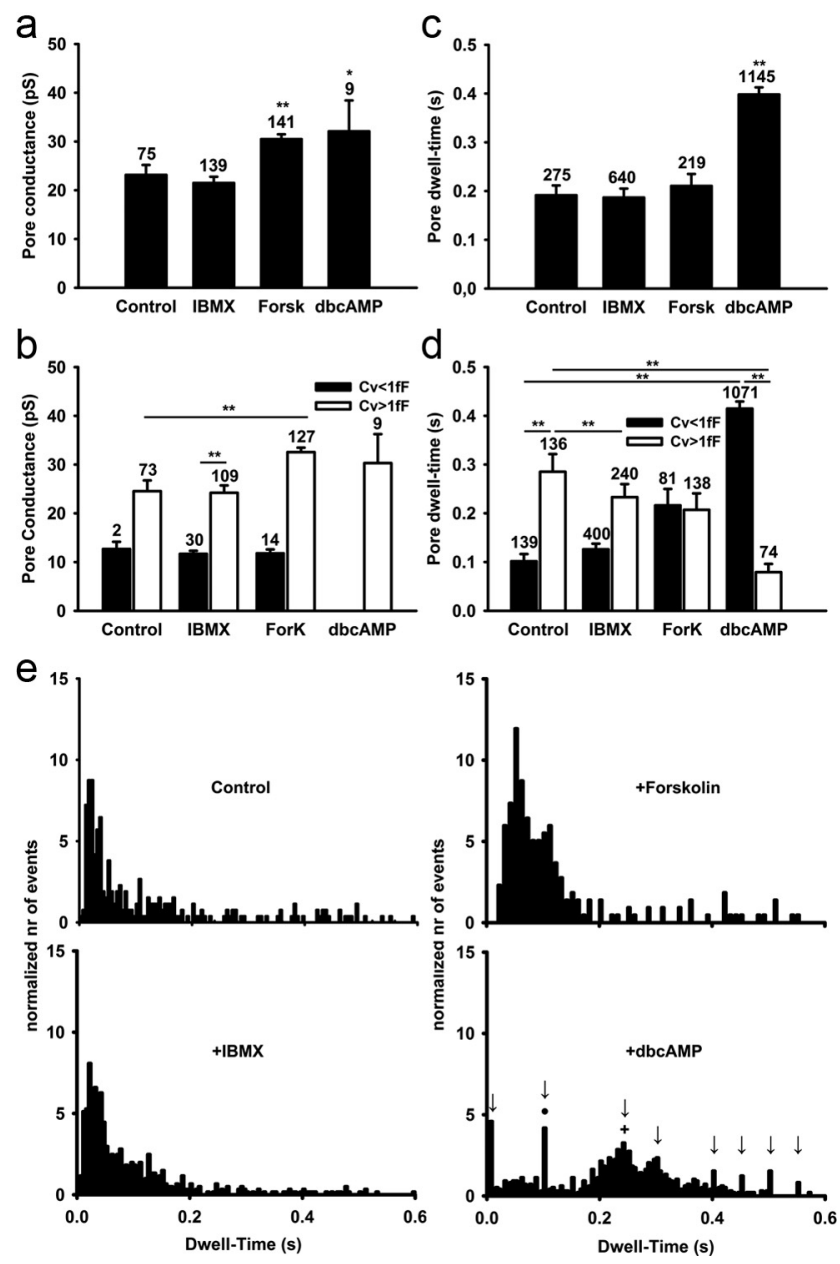

Figure 4. cAMP-increasing agents affect the fusion pore conductance and the pore dwell time. $\boldsymbol{a}$, The average $G_{p}$, determined for reversible events with measurable crosstalk between Re and Im traces in controls, was $23 \pm 2 \mathrm{pS}$ ( $n=75$ events). The addition of IBMX, forskolin, and dbcAMP increased the average $G_{p}$ to $21 \pm 1 \mathrm{pS}(n=139$ events; $p=0.3), 30 \pm 1 \mathrm{pS}(141$ events; $p<0.001)$, and $32 \pm 6 \mathrm{pS}(n=9$ events; $p<0.05)$, respectively. Values are mean \pm SEM. $\boldsymbol{b}$, The average fusion pore dwell time of controls was $0.19 \pm 0.02 \mathrm{~s}(n=275$ events) and remained unchanged after the addition of IBMX and forskolin $(0.19 \pm 0.02 s ; n=640$ events and $0.21 \pm 0.02 \mathrm{~s} ; n=219$ events, respectively). dbcAMP treatment increased the average fusion pore dwell time to $0.40 \pm 0.02 \mathrm{~s}(n=1145$ events, $p<0.001)$. Values are mean \pm SEM. c, Fusion pore conductance displayed as a function of $C_{v}>1 \mathrm{fF}$ (white columns) and $C_{v}<1 \mathrm{fF}$ (black columns). $\boldsymbol{d}$, Changes in fusion pore dwell time displayed as a function of $C_{v}>1 \mathrm{fF}$ (white columns) and $C_{v}<1 \mathrm{fF}$ (black columns).e, The frequency distribution of fusion pore dwell times in controls and after the addition of CAMP increasing agents. Arrows in the panel showing the distribution of fusion pore dwell times after the addition of dbcAMP (+dbcAMP) point to the modal values of the dwell times, which belong to the respective bursts. Two modal dwell times, which are marked with the cross and the dot, denote two bursts, shown in Figure $5 a, b .{ }^{*} p<$ 0.05 . ${ }^{* *} p<0.01$.

open fusion state, which we calculated as the sum of all fusion pore dwell times divided by the total recording time, increased after dbcAMP stimulation threefold, from $0.02(n=16$ cells) to 0.07 ( $n=7$ cells). In contrast, IBMX ( $n=10$ cells $)$ and forskolin ( $n=5$ cells $)$ stimulation did not significantly affect the probability of open fusion pore state ( 0.02 and 0.03 , respectively). Moreover, the cAMP-mediated effects of fusion pore dwell time depended on the $\mathrm{C}_{\mathrm{v}}$ amplitude. In controls, fusion pore dwell time was shorter for events with $\mathrm{C}_{\mathrm{v}}<1 \mathrm{fF}$ than with $\mathrm{C}_{\mathrm{v}}>1 \mathrm{fF}$ (Fig. 4d).

Frequency histograms of fusion pore dwell time (Fig. 4e) show that, in controls and after simulation with IBMX, distributions of fusion pore dwell times are similar (modal peaks at $\sim 0.03 \mathrm{~s}$ ). However, after stimulation with forskolin, fusion pore dwell time distribution shifted to higher values (second peak at $\sim 0.07 \mathrm{~s}$ ). After stimulation with dbcAMP, the distribution of fusion pore dwell times was different. Instead of a single or double mode distribution, we observed several modes (Fig. 4e, bottom right). Each of the modal peaks (Fig. $4 e$, bottom right, arrows) denotes a particular burst of events. Multimodality was observed also for separated data of $\mathrm{C}_{\mathrm{v}}<1 \mathrm{fF}$ and $\mathrm{C}_{\mathrm{v}}>1 \mathrm{fF}$ (data not shown). The prolonged fusion pore dwell time, observed after the stimulation with forskolin and dbcAMP, is consistent with previous reports (Ohara-Imaizumi et al., 2002; Gandhi and Stevens, 2003; Perrais et al., 2004; Thorn and Parker, 2005). Our results indicate that the stimulation with a low concentration of IBMX and forskolin is not sufficient to affect fusion pore dwell time. On the other hand, the mean dwell time of $\sim 250 \mathrm{~ms}$ after dbcAMP stimulation is similar to the reported value after depolarization with $\mathrm{KCl}$ (Vardjan et al., 2007).

The addition of dbcAMP elicits periodicity of transient fusion events within a burst

The increased intracellular level of cAMP elicited the periodicity of transient fusion events, which appeared in bursts (Figs. $2 f$ and Fig. $5 a, b)$. Within a burst, the transient fusion pore events represent repetitive reopening of the single vesicle fusion pore as indicated by practically identical $\mathrm{C}_{\mathrm{v}}$ amplitudes (see also Fig. $2 f$ ). Moreover, fusion pore dwell times of the repetitive reversible events in the same burst were relatively constant, contributing to the distinct modal peaks seen in Figure 4e, bottom right) (Henkel et al., 2000 and Stenovec et al., 2004). To study periodicity of transient fusion events in more detail, we determined the burst parameters. We considered a burst to be composed of at least five transient events, with at most $5 \mathrm{~s}$ in between ensuing events. In controls, $42 \%$ of transient fusion events occurred in bursts ( $n=$ 115 events in bursts). The percentage of events appearing in bursts increased to $53 \%$ ( $n=338$ events in bursts) after IBMX stimulation and to $70 \%(n=153$ events in bursts $)$ after forskolin stimulation. After dbcAMP stimulation, almost all events appeared in bursts ( $\sim 94 \% ; n=1078$ events in bursts). We then measured the time between ensuing events within bursts. The distribution of these, before stimulation, was complex (Fig. 5c). In contrast, stimulation with dbcAMP resulted in a bell-shaped distribution (Fig. $5 d, e$ ), indicating that the fusion pores reopened at predictable times within a given patch of membrane where the periodic behavior was recorded. To confirm the periodicity, we fitted the distributions with Gaussian curves (Fig. 5d,e) with mean values of $0.465 \pm 0.001 \mathrm{~s}$ and $1.166 \pm 0.002 \mathrm{~s}$. Similar values were reported previously (Stenovec et al., 2004).

Then we analyzed the relationship between the number of transient fusion events within a burst and the duration of the burst (Fig. $5 f$ ). In bursts after cAMP stimulation, we observed that the number of transient fusion events was correlated with the duration of the burst ( $r=0.76 ; n=44$ bursts), with the average frequency of $0.56 \pm 0.08$ events/s in bursts. Figure $5 f$ shows that the majority of bursts that occurred after the addition of cAMPincreasing agents had increased the number of events per burst and prolonged burst duration compared with controls. The average number of transient fusion events in a burst increased from $14 \pm 4$ events in controls ( $n=115$ events in 8 bursts $)$ to $17 \pm 3$ events after addition of IBMX ( $n=338$ events in 19 bursts), to $29 \pm 20$ events after addition of forskolin $(n=153$ events in 8 bursts) and to $27 \pm 6$ events after addition of dbcAMP $(n=1078$ events in 17 bursts). The average burst duration was similar in 
a
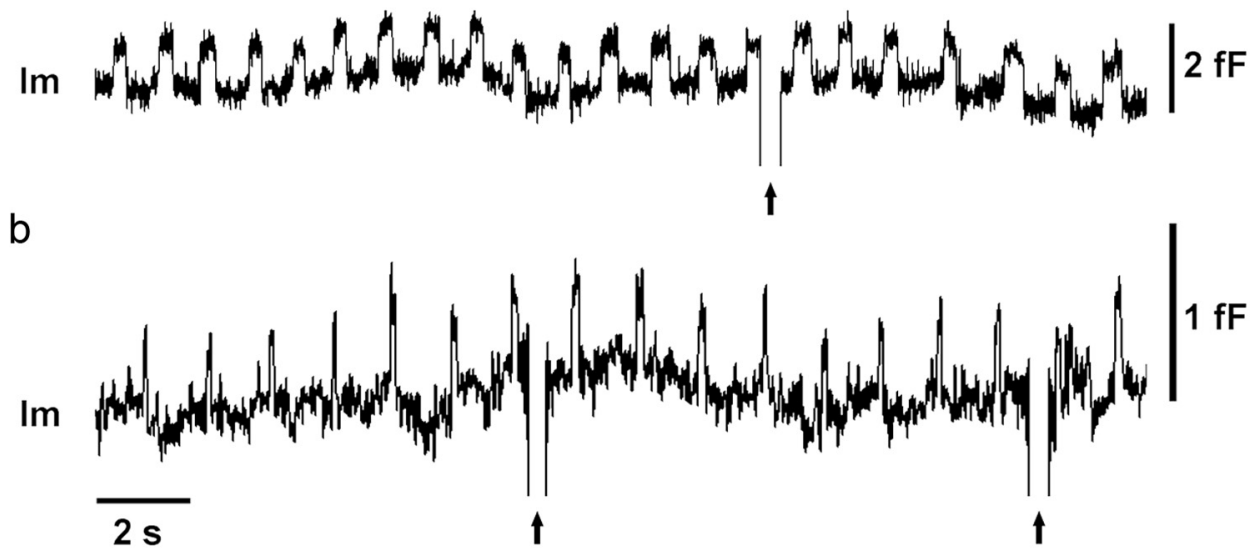

C

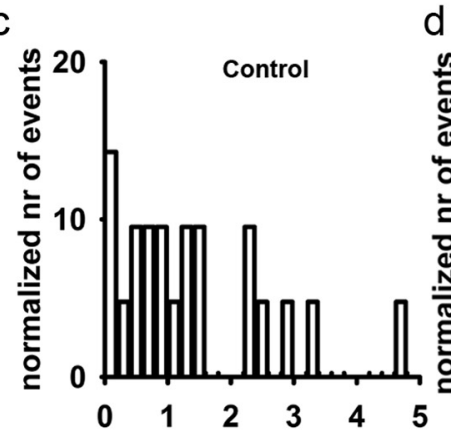

d

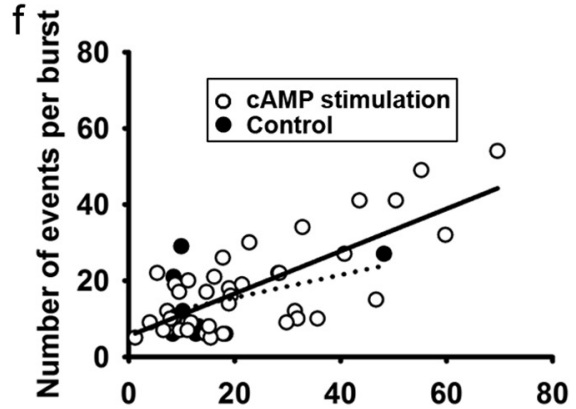

Time in between events (s)
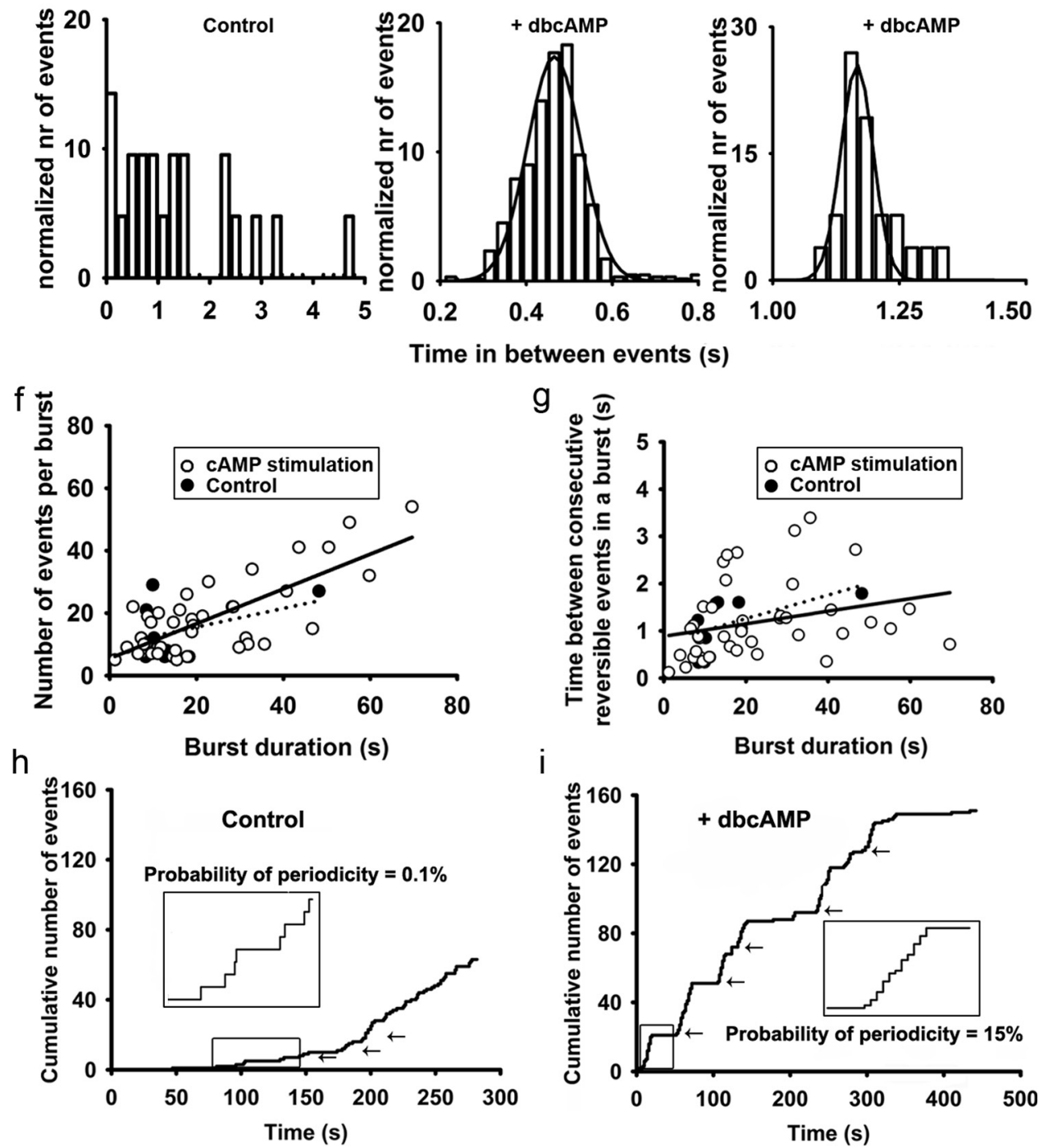

Figure 5. The addition of dbcAMP results in rhythmic reopening of the same fusion pore. $\boldsymbol{a}, \boldsymbol{b}$, Two epochs of the representative Im traces showing rhythmic fusion pore activity in two different cells after the addition of dbcAMP. This activity was part of two bursts (Fig. 1e for definition) with durations of 180 and $41 \mathrm{~s}$. $\boldsymbol{c}-\boldsymbol{e}$, Representative histograms of times in between ensuing transient exocytic events within a burst in controls $(\boldsymbol{c})$ and after the addition of dbcAMP (d,e). The histogram of controls shows a random distribution, whereas histograms after the addition of dbcAMP (which are partially shown in $\boldsymbol{a}, \boldsymbol{b}$ ) appear normally distributed and were fitted with Gaussian curves with the mean values of $0.465 \pm 0.001 \mathrm{~s}$ ( $n=645$ events) and $1.166 \pm 0.002 \mathrm{~s}$ ( $n=26$ events), respectively. $\boldsymbol{f}$, The number of reversible events in a burst depends on the burst duration. The control data points were fitted with the regression line (dotted line) with parameters: $y$ (number of events per burst) $=(0.30 \pm 0.27) \times x$ (burst duration in seconds) $+(10 \pm 6)$ (correlation coefficient $r=0.41, n=8$ bursts, $p=0.3)$ and after stimulation with cAMP (solid line): $y$ (number of events per burst) $=(0.56 \pm 0.08) \times x$ (burst duration in seconds) $+(6 \pm 2)$ (correlation coefficient $r=0.76, n=44$ bursts, $p<0.001)$. The number of bursts of controls is much reduced. $\boldsymbol{g}$, The time between consecutive reversible events in a burst did not depend on the burst duration. Control data points were fitted with the regression line (dotted line) with parameters: (Figure legend continues.) 


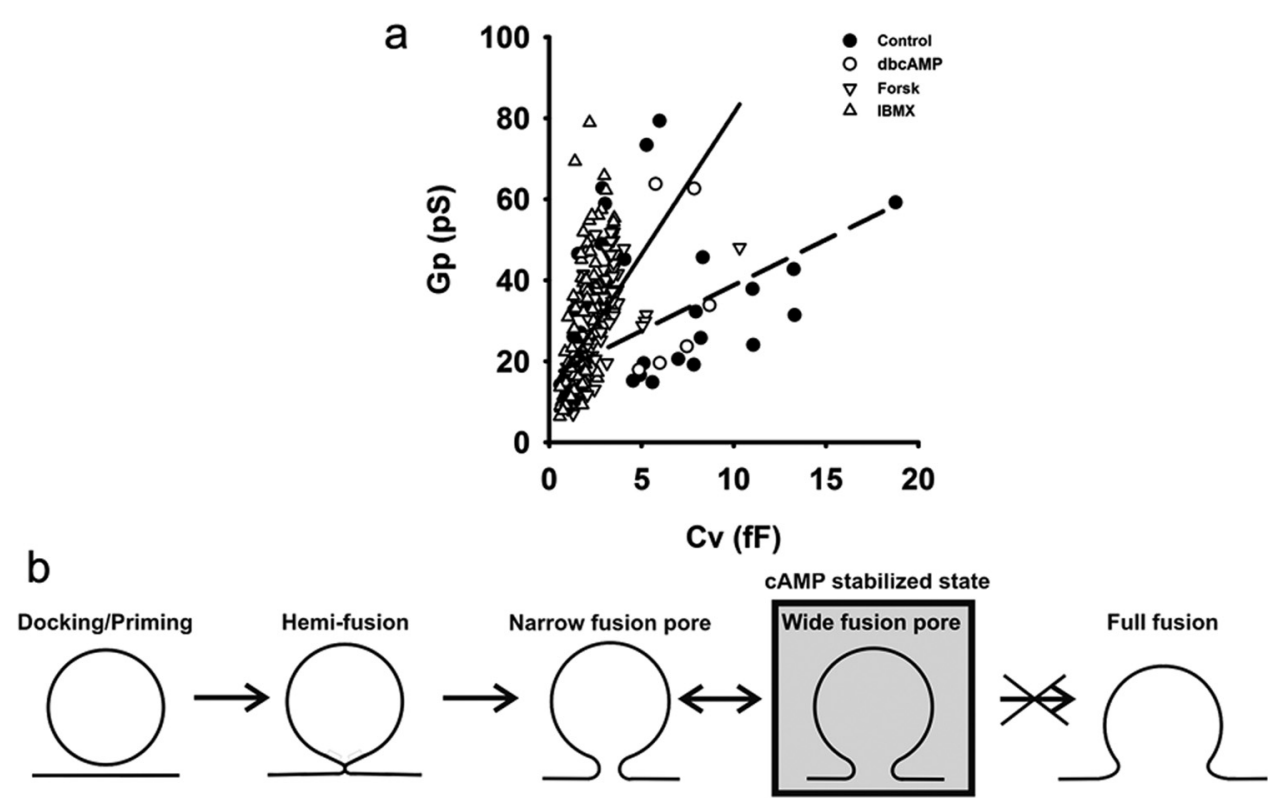

Figure 6. The presence of cAMP-increasing agents affects the relationship between the fusion pore diameter and the vesicle diameter. $\boldsymbol{a}$, Scatter plot diagram of fusion pore conductance versus vesicle capacitance of respective reversible events in controls (full circles) and after the addition of cAMP increasing agents (empty symbols). Respective data points were best fitted with: $y\left(\mathrm{G}_{\mathrm{p}}\right)=$ $(2.3 \pm 0.5) \times x\left(C_{v}\right)+(16 \pm 2)$ (control, dashed line, $\left.r=0.48\right)$ and $y\left(G_{\mathrm{p}}\right)=(7.0 \pm 0.5) \times x\left(C_{v}\right)+(11 \pm 1)$ (cAMP-increasing agents, solid line, $\left.r=0.61\right)$. Both slopes are significantly different from each other $(p<0.001)$. Significance was tested using one-way ANCOVA for two independent samples. $\boldsymbol{b}$, Model describing the effect of cAMP on exocytotic cycle of lactotroph vesicles.

control and in IBMX-stimulated condition $(\sim 18 \mathrm{~s})$, whereas after forskolin and dbcAMP stimulations, burst durations were prolonged ( $\sim 24 \mathrm{~s}$ and $\sim 33 \mathrm{~s}$, respectively; data not shown). We also analyzed the relationship between the time between consecutive transient events within a burst and burst duration, which showed a poor correlation ( $r=0.29 ; n=50$ bursts) and slope near $0(0.01 \pm 0.007$; Fig. $5 g)$. The majority of bursts recorded in the presence of elevated cAMP exhibit longer periods between consecutive transient events in addition to the prolonged burst durations, compared with controls (Fig. $5 g$ ). Therefore, the burst duration is related to the number but not the time in between consecutive transient fusion events. Figure $5 h, i$ shows cumulative numbers of transient events in two representative recordings. The appearance of bursts both in control and in dbcAMPstimulated conditions are highlighted in insets, respectively. In controls, the time between consecutive events is rarely periodic with the probability of periodicity of $0.1 \%$, calculated as the time in which reversible events were periodic, divided by the total time of recordings (see Materials and Methods). However, the inset of the dbcAMP-stimulated recording shows highly periodic transient exocytic events. The overall probability of periodicity after the addition of dbcAMP was $15 \%$, much more than in spontaneous conditions, where it was $0.1 \%$.

$\leftarrow$

(Figure legend continued.) $\quad y$ (time between consecutive reversible events in a burst in seconds $)=(0.025 \pm 0.015) \times x$ (burst duration in seconds) $+(0.8 \pm 0.3)$ (correlation coefficient $r=0.57, n=8$ bursts, $p=0.1)$; and after cAMP stimulation, data points were fitted with the regression line (solid line) with parameters: $y$ (time between consecutive reversible events in a burst in seconds $)=(0.013 \pm 0.007) \times x$ (burst duration in seconds $)+(0.9 \pm 0.2)$ (correlation coefficient $r=0.27, n=44$ bursts, $p=0.08$ ). The burst duration of controls was typically $<20 \mathrm{~s}$. $\boldsymbol{h}$, The cumulative number of reversible events as a function of time in a representative control cell. Arrows indicate bursts of reversible events. Inset, Magnified epoch (rectangle) where the time between ensuing reversible events is random. $\boldsymbol{i}$, The cumulative number of reversible events as a function of time in a representative cell after the addition of $\mathrm{dbcAMP}$. Arrows indicate bursts of reversible events. Inset, Magnified burst (rectangle) with remarkably constant time between ensuing reversible events.
These results indicate that dbcAMP stimulation not only increases the frequency of transient exocytic events but also affects the nature of their appearance: transient exocytic events become periodic, with periodic fusion pore dwell times and more frequently appear in bursts.

\section{cAMP stabilizes transient, widely open fusion pores}

The results shown in Table 1 demonstrate that dbcAMP decreases the fraction of transient exocytic events with relatively narrow (measurable) fusion pores. Moreover, the remaining transient exocytic events with measurable fusion pores exhibit increased diameters, compared with controls (Fig. 4a). Both results indicate that the addition of dbcAMP promotes wider fusion pores. Previously, we observed that fusion pore diameter is related to the diameter of vesicles (Jorgačevski et al., 2010). To check the possibility that the elevation of cAMP influences a previously observed relationship, we plotted $C_{v}$ and the respective $G_{p}$ for each event in controls and after the addition of cAMP-increasing agents (Fig. $6 a$ ). The data points were best fitted with linear regressions with the following slopes: $2.3 \pm 0.5 \mathrm{pS} / \mathrm{fF}$ (control) and $7.0 \pm 0.5 \mathrm{pS} / \mathrm{fF}$ (cAMP-increasing agents) $(p<0.001)$. These results show that a vesicle of a given $\mathrm{C}_{\mathrm{v}}$ (diameter) may attain a threefold larger $G_{p}$ (wider fusion pore) in the presence of a cAMP-increasing agent (Fig. 6a).

\section{Discussion}

Regulated exocytosis consists of several distinct stages (Coorssen and Zorec, 2012). The key finding of this work is that cAMP stabilizes a stage, where the vesicle fusion pore transiently opens to relatively wide diameters but has a reduced probability to enter into the full-fusion exocytic stage (Fig. 6b). Stabilization of a particular stage may represent a rate-limiting step for vesicle cargo release, implying that secretion can be regulated at the postfusion state (Rahamimoff and Fernandez, 1997; Barg et al., 2002; Tsuboi and Rutter, 2003; Obermüller et al., 2005; Hanna et al., 2009; Thorn, 2009; Jorgačevski et al., 2011). This condition can 
be attained by regulating fusion pore gating (kinetics) and by regulating fusion pore diameter (Staal et al., 2004; Stenovec et al., 2004; Vardjan et al., 2007; Jorgačevski et al., 2008, zharv; 232010Zhang and Jackson, 2008), as demonstrated in the present work for cAMP modulation of regulated exocytosis.

Hormone-release studies have shown that cAMP-elevating agents stimulate PRL release from pituitary cells at relatively low forskolin and dbcAMP concentrations, whereas at higher concentrations an inhibition of PRL release was recorded (Fig. 1). The latter finding contrasts with previous studies, where IBMX increases the content of cAMP in cells and also the release of PRL in a dose-dependent manner (Gonzalez-Iglesias et al., 2006). In the present work, elevated forskolin $(50 \mu \mathrm{M})$ and dbcAMP $(>10$ $\mathrm{mM}$ ) concentrations are inhibitory for PRL release (Fig. 1). Among many possible mechanisms, the inhibition of PRL release at elevated levels of cAMP may be the result of direct cAMPmediated modulation of the exocytic machinery (Sikdar et al., 1990, 1998; Hanna et al., 2009).

\section{cAMP increases the occurrence of transient exocytic events}

As shown previously (Zorec et al., 1991; Jorgačevski et al., 2008, 2011), we recorded unitary exocytic events in lactotrophs (Figs. 2 and 5). The amplitude of $\sim 1 \mathrm{fF}$ of these events is consistent with the view that they represent peptidergic vesicles interacting with the plasma membrane (Jorgačevski et al., 2011). Two kinds of discrete increases in $\mathrm{C}_{\mathrm{m}}$ were present: irreversible, representing full-fusion, and reversible, representing the transient mode of exocytosis (Fig. 2). Interestingly, cAMP-increasing agents did not increase the frequency of the former, but only the frequency of the latter (Figs. 2 and 3). The increased frequency of transient events is consistent with the increased PRL release recorded in these cells (Fig. 1). Furthermore, transient exocytic events exhibited wider fusion pore diameters and prolonged fusion pore dwell times (Fig. 4), all facilitating the exit of vesicle cargo into the extracellular space. However, the relative reduction of the occurrence of discrete irreversible steps in $\mathrm{C}_{\mathrm{m}}$ observed in the presence of cAMP-elevating agents (Fig. 2e), indicates that vesicle discharge may not attain full rates because it is hindered by the inability of transient exocytic events transiting into the fullfusion stage of regulated exocytosis (Fig. 6b). This condition is likely reflected in reduced rates of PRL release recorded at relatively high dbcAMP concentrations (Fig. 1). These results are in agreement with the decrease in cAMP-dependent full-fusion events in $\beta$-cells (Hanna et al., 2009). As in our experiments, where cAMP-increasing agents increase the frequency of transient exocytic events (Fig. 2d,e), a similar augmentation of the occurrence of transient exocytotic events was observed in PC12, chromaffin, and pancreatic $\beta$-cells (Wang et al., 2003; MacDonald et al., 2006; Hanna et al., 2009), but not in islet cells (Hatakeyama et al., 2006). Furthermore, Cochilla et al. (2000) have shown that the increase of intracellular cAMP does not affect the number of plasma membrane fusion sites. Thus, the enhanced, cAMP-stimulated PRL release observed (Fig. 1b) (Gonzalez-Iglesias et al., 2006) is the result of the increased secretion of PRL per fusion site, possibly via more efficient vesicle discharge (i.e., increased frequency of reversible exocytic events and increased $\mathrm{G}_{\mathrm{p}}$; Figs. $2 d$ and Fig. $4 a$ ). Most likely, the aforementioned cAMP-stimulated PRL release cannot be attributed to the compound exocytosis (Vardjan et al., 2009) because the results on the vesicle sizes (estimated from $\mathrm{C}_{\mathrm{v}}$; Fig. 3) do not support this conclusion.

The fusion pore has long been considered an unstable intermediate leading to complete merger of the vesicle membrane with the plasma membrane (Heuser and Reese, 1973). However, recent evidence indicates that the fusion pore can exhibit remarkable stability and can fluctuate between several open and closed states (Vardjan et al., 2007; Jorgačevski et al., 2010). The results in this study show that cAMP may stabilize one of these intermediates (i.e., transient fusion pore openings with relatively wide diameters and prolonged dwell times). However, this intermediate unlikely proceeds to the full-fusion stage of exocytosis (Fig. 6b) and thus represents a hindrance for the fastest rates of PRL release. A similar stabilization, albeit with fusion pore narrowing, was observed in lactotrophs transfected with Munc 18-1 mutants (Jorgačevski et al., 2011) and in lactotrophs exposed to $\mathrm{Al}^{3+}$ (Calejo et al., 2012).

The increase of intracellular cAMP resulted in fusion of larger vesicles in melanotrophs (Sikdar et al., 1998). Our results show that the amplitudes of $\mathrm{C}_{\mathrm{v}}$ of transient events are similar in control and cAMP conditions in a given patch of membrane (Figs. $2 b, f$ and 3). However, when we plotted the $\mathrm{C}_{\mathrm{v}}$ amplitudes of all recorded events, the amplitudes of $\mathrm{C}_{\mathrm{v}}$ appeared to consist of two vesicle populations being engaged in regulated exocytosis. The recalculated average vesicle diameters were 145 and $225 \mathrm{~nm}$ (see Materials and Methods), corresponding well with the size of PRL-containing vesicles (Smets et al., 1987; Angleson et al., 1999). Stimulation with cAMP-increasing agents increased the occurrence of the smaller amplitude vesicles (Fig. 4c). Why cAMP-mediated effects are related to mainly the smaller-sized vesicles interacting with the plasma membrane is unclear but may relate to the observation that fusion pore diameter attained at equilibrium depends on vesicle diameter and on the intrinsic shape of membrane constituents in the region of the fusion pore (Jorgačevski et al., 2010). The latter could be affected by cAMPdependent alteration of the local phospholipid environment $(\mathrm{Su}$ et al., 2012), whereas size modulation of vesicles of different diameters was observed also in cells treated by Munc 18-1 mutations (Jorgačevski et al., 2011).

\section{cAMP-increasing agents elevate the fusion pore conductance and invoke rhythmicity}

The release of vesicle content through a transient fusion pore depends on the effective diameter and the lifetime of the fusion pore. Previous studies have shown that $\mathrm{KCl}$ and hyposmotic stimulation affects both parameters in rat lactotrophs (Vardjan et al., 2007; Jorgačevski et al., 2008). In the present work, 25\% of transient events, measured in control conditions, exhibited fusion pores, with the diameters $<3 \mathrm{~nm}$ (a limitation of our experimental setup; Debus and Lindau, 2000) (Table 1), as reported and too narrow for the exit of PRL from the vesicle (Vardjan et al., 2007). Stimulation with cAMP-increasing agents decreased the percentage of narrow fusion pores and increased the average fusion pore diameter of measurable fusion pores (Table 1; Fig. 4). Only stimulation with IBMX failed to result in a statistically significant increase of the average fusion pore diameter. This failure could be the result of the slower time course of the cAMP increase that follows this type of stimulation. The other possibility is that the level of cAMP concentration achieved with this stimulation is below the level of that achieved with forskolin and dbcAMP. In agreement with these two notions, stimulation with dbcAMP had the most robust effects on the kinetics and conductance of the fusion events (Figs. 4, 5, and 6). MacDonald et al. (2006) failed to observe changes in $\mathrm{G}_{\mathrm{p}}$ after the stimulation with $5 \mu \mathrm{m}$ forskolin, which could be the result of the different concentration used or the different cell model. 


\section{Rhythmicity of transient fusion events}

Our results show that the average fusion pore dwell time significantly increased only after the stimulation with dbcAMP (Figs. 4 and $6 a$ ). This result may reflect the fact that the intracellular cAMP concentration must reach a threshold value to increase the fusion pore dwell time. The distribution of fusion pore dwell times shows that in controls the modal peak is similar to the one reported (Stenovec et al., 2004) and is not changed after the stimulation with IBMX (Fig. 4c). Stimulation with forskolin shifted the modal peak dwell time to a higher value. On the other hand, stimulation with dbcAMP resulted in several modal values, which represent the distribution of fusion pore dwell times within bursts (Figs. $2 f$ and $5 a, b$ ) and are similar to the observations of stimulated fission pore open states (Henkel et al., 2000). Moreover, time in between ensuing exocytic events was regular and could be fitted with a Gaussian curve (Fig. $5 d, e$ ). Amperometric measurements in giant dopamine neurons of freshwater snail showed a similar phenomenon: a bursting of periodic exocytotic events (Chen et al., 1996). The physiological significance of this periodic exocytic activity is still unknown but may involve cationic fluxes through the fusion pore and the vesicle membrane, as previously modeled (Kabaso et al., 2012).

In conclusion, the regulation of cAMP-mediated PRL-release is much more complicated than initially thought. Even though the increase in cAMP to a certain level stimulates PRL release, at much higher levels of cAMP, the PRL release is significantly reduced mainly because of a decrease in the full-fusion exocytic events. We attribute transient increase in PRL release to stabilized fusion pores, which open more frequently, have on average prolonged dwell time and wider diameters but are unable to transit into the full-fusion exocytic state.

\section{References}

Alés E, Tabares L, Poyato JM, Valero V, Lindau M, Alvarez de Toledo G (1999) High calcium concentrations shift the mode of exocytosis to the kiss-and-run mechanism. Nat Cell Biol 1:40-44. CrossRef Medline

Alvarez de Toledo G, Fernández-Chacón R, Fernández JM (1993) Release of secretory products during transient vesicle fusion. Nature 363:554-558. CrossRef Medline

Angleson JK, Cochilla AJ, Kilic G, Nussinovitch I, Betz WJ (1999) Regulation of dense core release from neuroendocrine cells revealed by imaging single exocytotic events. Nat Neurosci 2:440-446. CrossRef Medline

Barg S, Olofsson CS, Schriever-Abeln J, Wendt A, Gebre-Medhin S, Renström E, Rorsman P (2002) Delay between fusion pore opening and peptide release from large-dense-core vesicles from neuroendocrine cells. Neuron 33:287-299. CrossRef Medline

Ben-Tabou S, Keller E, Nussinovitch I (1994) Mechanosensitivity of voltage-gated calcium currents in rat anterior pituitary cells. J Physiol 476:29-39. Medline

Breckenridge LJ, Almers W (1987) Currents through the fusion pore that forms during exocytosis of a secretory vesicle. Nature 328:814-817. CrossRef Medline

Calejo AI, Jorgačevski J, Silva VS, Stenovec M, Kreft M, Gonçalves PP, Zorec R (2012) Aluminum-induced changes of fusion pore properties attenuate prolactin secretion in rat pituitary lactotrophs. Neuroscience 201:5766. CrossRef Medline

Chen G, Gutman DA, Zerby SE, Ewing AG (1996) Electrochemical monitoring of bursting exocytotic events from the giant dopamine neuron of Planorbis corneus. Brain Res 733:119-124. CrossRef Medline

Cochilla AJ, Angleson JK, Betz WJ (2000) Differential regulation of granuleto-granule and granule-to-plasma membrane fusion during secretion from rat pituitary lactotrophs. J Cell Biol 150:839-848. CrossRef Medline

Coorssen JR, Zorec R (2012) Regulated exocytosis per partes. Cell Calcium 52:191-195. CrossRef Medline

Debus K, Lindau M (2000) Resolution of patch capacitance recordings and of fusion pore conductances in small vesicles. Biophys J 78:2983-2997. CrossRef Medline

Fernandez JM, Neher E, Gomperts BD (1984) Capacitance measurements reveal stepwise fusion events in degranulating mast cells. Nature 312:453455. CrossRef Medline

Fesce R, Grohovaz F, Valtorta F, Meldolesi J (1994) Neurotransmitter release: fusion or "kiss-and-run"? Trends Cell Biol 4:1-4. CrossRef Medline

Gandhi SP, Stevens CF (2003) Three modes of synaptic vesicular recycling revealed by single-vesicle imaging. Nature 423:607-613. CrossRef Medline

Gonzalez-Iglesias AE, Jiang Y, Tomiæ M, Kretschmannova K, Andric SA, Zemkova H, Stojilkovic SS (2006) Dependence of electrical activity and calcium influx-controlled prolactin release on adenylyl cyclase signalling pathway in pituitary lactotrophs. Mol Endocrinol 20:2231-2246. CrossRef Medline

Gonzalez-Iglesias AE, Murano T, Li S, Tomiæ M, Stojilkovic SS (2008) Dopamine inhibits prolactin release in pituitary lactotrophs through pertussis toxin-sensitive and -insensitive signaling pathways. Endocrinology 149:1470-1479. CrossRef Medline

Hanna ST, Pigeau GM, Galvanovskis J, Clark A, Rorsman P, MacDonald PE (2009) Kiss-and-run exocytosis and fusion pores of secretory vesicles in human $\beta$-cells. Pflugers Arch 457:1343-1350. CrossRef Medline

Hatakeyama H, Kishimoto T, Nemoto T, Kasai H, Takahashi N (2006) Rapid glucose sensing by protein kinase A for insulin exocytosis in mouse pancreatic islets. J Physiol 570:271-282. CrossRef Medline

Henkel AW, Meiri H, Horstmann H, Lindau M, Almers W (2000) Rhythmic opening and closing of vesicles during constitutive exo- and endocytosis in chromaffin cells. EMBO J 19:84-93. CrossRef Medline

Heuser JE, Reese TS (1973) Evidence for recycling of synaptic vesicle membrane during transmitter release at the frog neuromuscular junction. J Cell Biol 57:315-344. CrossRef Medline

Jahn R, Lang T, Südhof TC (2003) Membrane fusion. Cell 112:519-533. CrossRef Medline

Jorgačevski J, Stenovec M, Kreft M, Bajić A, Rituper B, Vardjan N, Stojilkovic S, Zorec R (2008) Hypotonicity and peptide discharge from a single vesicle. Am J Physiol Cell Physiol 295:624-631.

Jorgačevski J, Fošnarič M, Vardjan N, Stenovec M, Potokar M, Kreft M, Kralj-Iglič V, Iglič A, Zorec R (2010) Fusion pore stability of peptidergic vesicles. Mol Membr Biol 27:65-80. CrossRef Medline

Jorgačevski J, Potokar M, Grilc S, Kreft M, Liu W, Barclay JW, Bückers J, Medda R, Hell SW, Parpura V, Burgoyne RD, Zorec R (2011) Munc18-1 tuning of vesicle merger and fusion pore properties. J Neurosci 31:9055-9066. CrossRef Medline

Kabaso D, Calejo AI, Jorgačevski J, Kreft M, Zorec R, Iglič A (2012) Fusion pore diameter regulation by cations modulating local membrane anisotropy. Sci World J 2012:983138. CrossRef Medline

Kostic TS, Tomiæ M, Andric SA, Stojilkovic SS (2002) Calciumindependent and cAMP-dependent modulation of soluble guanylyl cyclase activity by G-protein-couple receptors in pituitary cells. J Biol Chem 277:16412-16418. CrossRef Medline

Kreft M, Zorec R (1997) Cell-attached measurements of attofarad capacitance steps in rat melanotrophs. Pflugers Arch 434:212-214. CrossRef Medline

Lollike K, Lindau M (1999) Membrane capacitance techniques to monitor granule exocytosis in neutrophils. J Immunol Methods 232:111-120. CrossRef Medline

Lollike K, Borregaard N, Lindau M (1995) The exocytotic fusion pore of small granules has a conductance similar to an ion channel. J Cell Biol 129:99-104. CrossRef Medline

MacDonald PE, Braun M, Galvanovskis J, Rorsman P (2006) Release of small transmitters through kiss-and-run fusion pores in rat pancreatic $\beta$ cells. Cell Metab 4:283-290. CrossRef Medline

Neher E, Marty A (1982) Discrete changes of cell membrane capacitance observed under conditions of enhanced secretion in bovine adrenal chromaffin cells. Proc Natl Acad Sci U S A 79:6712-6716. CrossRef Medline

Obermüller S, Lindqvist A, Karanauskaite J, Galvanovskis J, Rorsman P, Barg $S$ (2005) Selective nucleotide-release from dense-core granules in insulin-secreting cells. J Cell Sci 118:4271-4282. CrossRef Medline

Ohara-Imaizumi M, Nakamichi Y, Tanaka T, Katsuta H, Ishida H, Nagamatsu S (2002) Monitoring of exocytosis and endocytosis of insulin secretory granules in the pancreatic $\beta$-cell line MIN6 using $\mathrm{pH}$-sensitive green fluorescent protein (pHluorin) and confocal laser microscopy. Biochem J 363:73-80. CrossRef Medline

Perrais D, Kleppe IC, Taraska JW, Almers W (2004) Recapture after exocy- 
tosis causes differential retention of protein in granules of bovine chromaffin cells. J Physiol 560:413-428. CrossRef Medline

Rahamimoff R, Fernandez JM (1997) Pre- and post-fusion regulation of transmitter release. Neuron 18:17-27. CrossRef Medline

Renström E, Eliasson L, Rorsman P (1997) Protein kinase A-dependent and -independent stimulation of exocytosis by cAMP in mouse pancreatic B-cells. J Physiol 502:105-118. CrossRef Medline

Sedej S, Rose T, Rupnik M (2005) cAMP increases $\mathrm{Ca}^{2+}$-dependent exocytosis through both PKA and Epac2 in mouse melanotrophs from pituitary slices. J Physiol 567:799-813. CrossRef Medline

Seino S, Shibasaki T (2005) PKA-dependent and PKA-independent pathways for cAMP-regulated exocyosis. Physiol Rev 85:1303-1342. CrossRef Medline

Sikdar SK, Zorec R, Mason WT (1990) cAMP directly facilitates Ca-induced exocytosis in bovine lactotrophs. FEBS Lett 273:150-154. CrossRef Medline

Sikdar SK, Kreft M, Zorec R (1998) Modulation of unitary exocytotic event amplitude by cAMP in rat melanotrophs. J Physiol 511:851-859. CrossRef Medline

Smets G, Velkeniers B, Finne E, Baldys A, Gepts W, Vanhaelst L (1987) Postnatal development of growth hormone and prolactin cells in male and female rat pituitary: an immunocytochemical light and electron microscopic study. J Histochem Cytochem 35:335-341. CrossRef Medline

Spruce AE, Breckenridge LJ, Lee AK, Almers W (1990) Properties of the fusion pore that forms during exocytosis of a mast cell secretory vesicle. Neuron 4:643-654. CrossRef Medline

Staal RG, Mosharov EV, Sulzer D (2004) Dopamine neurons release transmitter via a flickering fusion pore. Nat Neurosci 7:341-346. CrossRef Medline

Stenovec M, Kreft M, Poberaj I, Betz WJ, Zorec R (2004) Slow spontaneous secretion from single large dense-core vesicles monitored in neuroendocrine cells. FASEB J 18:1270-1272. CrossRef Medline
Stojilkovic SS, Tabak J, Bertram R (2010) Ion channels and signaling in the pituitary gland. Endocr Rev 31:845-915. CrossRef Medline

Su WM, Han GS, Casciano J, Carman GM (2012) Protein kinase A-mediated phosphorylation of Pah1p phosphatidate phosphatase functions in conjunction with the Pho85p-Pho80p and Cdc28p-cyclin B kinases to regulate lipid synthesis in yeast. J Biol Chem 40:3336433376. CrossRef Medline

Thorn P (2009) New insights into the control of secretion. Commun Integr Biol 2:315-317. CrossRef Medline

Thorn P, Parker I (2005) Two phases of zymogen granule lifetime in mouse pancreas: ghost granules linger after exocytosis of contents. J Physiol 563: 433-442. CrossRef Medline

Tsuboi T, Rutter GA (2003) Multiple forms of "kiss-and-run" exocytosis revealed by evanescent wave microscopy. Curr Biol 13:563-567. CrossRef Medline

Vardjan N, Stenovec M, Jorgačevski J, Kreft M, Zorec R (2007) Subnanometer fusion pores in spontaneous exocytosis of peptidergic vesicles. J Neurosci 27:4737-4746. CrossRef Medline

Vardjan N, Jorgačevski J, Stenovec M, Kreft M, Zorec R (2009) Compound exocytosis in pituitary cells. Ann N Y Acad Sci 1152:63-75. CrossRef Medline

Wang CT, Lu JC, Bai J, Chang PY, Martin TF, Chapman ER, Jackson MB (2003) Different domains of synaptotagmin control the choice between kiss-and-run and full-fusion. Nature 424:943-947. CrossRef Medline

Zhang Z, Jackson MB (2008) Temperature dependence of fusion kinetics and fusion pores in $\mathrm{Ca}^{2+}$-triggered exocytosis from PC12 cells. J Gen Physiol 131:117-124. CrossRef Medline

Zorec R, Sikdar SK, Mason WT (1991) Increased cytosolic calcium stimulates exocytosis in bovine lactotrophs. J Gen Physiol 97:473-497. CrossRef Medline 